\title{
How to Start A New Business in France - Justify the Idea of Starting A Ski Service Company in Grenoble France
}

\author{
Yu Tian \& Jingliang Chen \\ Business School, University of Shanghai for Science and Technology \\ 516 Jungong Rd, Shanghai 200093, China \\ E-mail: mr.tianyu@gmail.com
}

\begin{abstract}
The paper is mainly concerning two crucial strategy question for starting a new business within today's French business environment. They are which sector will be appropriate point to start and how to form the company. Deductive method is adopted to analyze the former and inductive approach is employed to explore the later. To make the argument robust, economics model, organizational behavior theories and accounting knowledge are widely used. Through the research work, the paper indicates that providing ski service could be a profitable business idea in Grenoble France, and the company should be organized in terms of hierarchy structure with flatting form, which could be achieved by job-enrichment. Finally, the paper demonstrates to entrepreneurs that although the economy performance of France is weak now days, some business still can be start as long as they are well arranged.
\end{abstract}

Keywords: France, Enterprise, CBR, Ski Service

\section{Introduction}

This report mainly focus on two question sets: first one is to justify the idea of starting a company which provides a clouts of services to those who spend their holiday in Alpe d'Huez ski resorts and the firm running business on tourist sector; second purpose is that if the proposed business set up, how to arrange its business activities to achieve success. Thus, the research work try to explore under today's French economy situation and its business culture, how to integrate different discipline within management study to set up a new business in an appropriate way.

Integrating different disciplines, it is a challenge to management study and it is necessary to conduct business activities, especially to start a new company with relative small size. Since most influential large companies in today's business world stemmed from small organization, and the sector in which they operate might be ignored in that age. Hence, through investigating current French economy situation based on economics analysis will be help to justify the proposed ideas. However, executive any business activities need rely on an organizational base, thus, arrangement of an enterprise is going to be another crucial requirement.

In order to clearly address the topic set, this report will follow the structure as below: Part I: methodology. In this part, it will demonstrate the way used to collect information and the problem might occur as well as the methods and framework employed to explore the topic. Part II: justify the ideal of proposed business. In this part, the work will concentrate on the analyzing French economy situation through employing economics theory and models as well as using relevant data. Part III: How to arrange the new company to achieve success. In this part, the discussion will highlight the way to organize an effective enterprise within the social and culture context. At the end of the report, it will give a conclusion based on the previous research activities.

\section{Methodology}

\section{The selected of framework and method}

The report will follow the PSETEL framework. In part II justify the idea of proposed business. The analysis work largely relies on deductive method since economics analysis is based on data interpretation and theory analysis. Hence, in that part the discussion focus on $\mathrm{P}$ (political factors), $\mathrm{E}$ (economic factors) and E(environmental factors); In part II, how o arrange the new business inductive method will be employed, since this method is a common way to create a rational and feasible arrangement for a new company through understanding S(social-culture), L(legal system) and T(technology). Thus, it is a mixed approach that employed in the whole report.

The strength and weakness o the selected framework as well as the reliability of outcome 
As R. Lynch argued that any PESTEL environmental analysis framework could provide two outcomes, they are proactive outcomes which can utilize/exploit opportunities or cope with/eliminate threats and reactive outcomes which is the awareness of events that cannot be controlled by organization but has to be reacted if it happens. In addition, according to current government models assumption, any successful plan is the result of analyzing and evaluating external environment. (Sorensen-Bentham T, 2006) All these points of view advocate PESTEL framework could be used to predict future through past and current events analysis. On the other hand, PESTEL framework inevitably has several backwards described by Johson \& Scholes in their literature (Sorensen-Bentham T, 2006) as 'some of the factors are very general and their impact might be difficult to specify' and 'it need to be understand that the analysis is looking at future impact of environmental factors which might be different from past impact of similar factors.' Thus, the work based on this framework is meaningful to the topic set. However, the significance of the finding could be undermined in some degree since the dynamic environment.

\section{Justify the idea of starting a ski resorts service company in Grenoble France}

The idea of ski resorts services company can be defined as an organization that provides a wide range of service including ski training course, ski equipment renting, booking accommodation and ski pass as well as hotel-resorts transportation service. In this part, it will focus on E (environmental factors), E (economic factors) and $\mathrm{P}$ (political factors) three aspects to exam this idea.

\section{The environment factors}

Starting the business in Grenoble has following three environmental reasons: firstly Grenoble is a historical city located 56km far from Aple d'Huez - one of the most beautiful ski resorts in Europe. It is the nearest city around Aple d'Heuz. Secondly, Grenoble is a city connected by fast train (TGV), through TGV, from Paris to Grenoble only takes 3 hours and it only cost 1 hour to reach Lyon. In addition Grenoble is surrounded by the highly developed motor-way network. All these advantages create an optimal location to start ski resort service business.

\section{The economics analysis}

Someone maybe argue that it is not a suitable time to start any new business activities in France since during recent years, the performance of French economy is relatively weak, which can be indicted by high ratio of unemployment with large amount jobless. (Insert Figure 1 and 2 Here)

Since second half of year 2001, the unemployment ratio began to increase from $8.5 \%$ to around $10 \%$ at 2005 , with the jobless from2, 300,000 to 2,700,000. This figure indirectly shows a number of small, median business collapses, for large organizations as Air France, Renault are still controlled by authority, which have not reduced large amount working opportunities. However, on account of high level of unemployment, it is the chance to find cheap labor to reduce cost and release the starting budge. This can be seen from the following labor participation model. (Insert Figure 3 Here)

Since French legal system only allows each labor work 39 hours a week, within minimum payment $€ 8$ per hour, the organization cannot prolong the working time with very low pay. Nevertheless, the high level unemployment which is characterized as structural or cyclical employment provides a large number of job-seekers. In the other word, the labor market does not clear because supply largely exceeds demand, so new firm access to hire ordinary labor with minimum payment. This could significantly reduce input cost.

Others might argue that the difficulties faced by French economy is caused by joining the Euro Zone, which make the monetary authority (basically it is central bank's responsibility) lose the ability to adjust interest rate and exercise inflation policy to active economy. The result of the effect includes insufficient demand that lead to slow GDP growth. In addition, the appreciation of Euro against US dollar even worsens this situation. Nevertheless, the paradox is the French real value of export in terms of US dollar increased from $\$ 325$ billions (2000) to $\$ 419$ billion (2004). (Insert Figure 4 Here)

Though the trend of Euro against other currency is still upward, to explain this phenomenon, it is worth of comparing the real GDP Growth ratio among main large economies. (Insert Figure 5, 6, 7, 8 Here)

According to these figures, China displays the highest growth rate at $9.1 \%$ in 2004, US was the second at $4.4 \%$, even the UK was $1.1 \%$ higher than France at $3.2 \%$ in 2004 . Thus, Euro is depreciate against other currency in terms of purchase power hold by the individual in those nations, thus the demand comes from outside of the France goes up. This can be displayed by demand - supply model. (Insert Figure 9 Here) 
This model shows that the relationship between price and demand is negatively correlated, ceteris paribus, the decrease of price lead to go to right alone the curve, however, the increase of purchase power of other large economics, especially, the tremendous growth in China causes the demand curve shift to right side at same price level. If the supply is not adjusted, the quantity goes up (Q3 - Q1) with the price increasing (P3 - P1), which can bring extra revenue (P1 P3 O1 O3). This could be proved by the boom in tourist factor in France. On account of ski resorts is closed related to tourist industry and the firms providing integrated ski service s rarely found, it is possible for this types if firm enjoying big market with less competition.

\section{The political factors}

The taxation level exercise by fiscal policy may be the real factor that inhibits the development of new small and media companies. The 'tax wedge' in 2004 is $40 \%$, including standard company tax $33.3 \%$, company payroll tax $0.15 \%-1.5 \%$ and the rest is social charges. (Insert Table 1 Here) This is the why labor cost is very high in France compared with the UK and USA. (Insert Table 2 Here)

Hence, according to investigating above three aspects, although high taxation level is harmful for new business, which could be compensated in some degree through well arranging the company, in all, the advantages and potential profit brought by the proposed business largely overweight the disadvantages, thus, ski resorts service could be a appropriate sector to start a new business.

\section{How to arrange the new company to achieve success}

Since start a ski resort service company is feasible and profitable, it still need consider the way to exercise this business activity with concerning $\mathrm{L}$ (legal factor), $\mathrm{T}$ (technology factor) and $\mathrm{S}$ (social culture) In a French background.

\section{The legal factor}

In France, it adopts a civil law system based on Roman law and with substantial reliance on codified law. There are 7 common company styles in France. (Gordon C, 1996) The most popular styles are the Societe Anonyme (SA) and the Societe a Responsabilite Limitee (SARL) form as well as the Societe en Nom Collecitif (SNC). To a new small firm, SARL style might be more favorable for following three reasons:

Firstly, SARL and SA form are limited liability to their capital contribution, but SNC is unlimited liability. Thus, considering the risk avoidance, in case, the business collapse, SARL can protect the founders benefit.

Secondly, within limited liability firm legal structure; compared with SA style, SARL is not composed to set up board of directors, in this sense, it could remove one layer within company design (this will be discussed later in the next heading).

Thirdly, compared with SA form, the minimum capital register requirement for SARL is only approximate $€ 9,000$. According to accounting discipline, this will bring at least two advantages:

1). Deposit less amount of register capital could largely release the new company from financial constrain. Since French company are willing to use debt finance rather than other method, this could reduce interest payment, thus, the financial risk is lower. This result can be seen from high interest cover and cash interest cover ratio and low gearing ratio. When the account statement of financial year is available (on the account of new starting company, financial statement only can be see next year).

2). Another two figure so called 'trade debtors' and 'account payable' measure the period require for a company to receive payment from their customer and make payment to their supplier. To a new start business, the former criterion might be big; on contrast, the later could be small. This is seen as that the efficiency of a company is unfavorable. Less register capital in turn enlarges a firm initial cash flow; this could reduce the impact induced by account in-efficiency.

Thus, based on accounting knowledge and the objective legal system, for a new start small business, SARL structure will be more favorable.

\section{The social culture and technological factor}

Any business activities cannot operate without concerning its specific culture background and the technology available to them. So when a new start company designs their job and structure, they need pay more attention to these factors since once these arrangements created, changing them will be very difficult.

In order to understanding French business culture clearly, it is necessary to compare that of the UK within Hofstede 5D model. This model is a powerful tool to analysis culture difference since it use scores to measure five main business culture indicators - they are PDI (power distance index), IDV (individualism), MAS 
(masculinity), UAI (uncertainty avoidance index) and LTO (long-term orientation) respectively, according to the comparison figure. (Insert Figure 10 Here)

IDV of French nearly fourfold that of the China, and the French are highly uncertainty avoidance reach the score 80, but they are very Feminist with low score in MAS indictor just above 40. This information at lease unfold two management secret formulas that the hierarchy structure may be more suitable to a company with most staff are French, and job-enrichment may be necessary to motivate them to improve their performance.

According to the result of Hofstede 5D model and the factor that the new start business is relatively small, the ideology behind the set up phase is that the company need adopt entrepreneurial structure. In a very real sense power and authority within the organization lie with the owner/manager. (Insert Figure 11 Here) On account of the business activities embrace ski skill training, ski equipment rent, booking accommodation and ski pass and Hotel-resort transportation service. In effect, the small business is still need employ $20-30$ staffs, hence, bear initial entrepreneurial structure ideology, the exact arrangement of company structure could take product-based structure. (Insert Figure 12 Here)

Employ this structure at least could achieve three goals: Firstly, product focus. To this new business, one type of service could be regard as one product; this arrangement could avoid any overlapping and cleat their job-description. Secondly, single head. Each service production has a unique person bear the responsibility of the unit performance. Thirdly, limited autonomy. Each divisional head will be accountable to the boss/manager for running of their business.

This kind of structure might be mire compatible to the French business culture described by Hostede 5D model scores, since it is high hierarchy controlled with job-role certain.

Organization structure significantly affect the job-design within the company, in turn job-design influence the decision of what kind of structure should be adopt or at least it impact on the efficiency of the created structure. The customer - hierarchy conflict model (Insert Figure 13 Here) clearly indicate that the customer experiences any organization horizontally, not vertically. However, the employees within an organization more care what they have done. To a firm providing service, customer service becomes virtual important. To solve this dilemma, job-enrichment needs to be concerned. According to Herzberg $(1968,1974)$, He identify six form of enrichment should be include in job-design; they are accountability, achievement, feedback, work pace, control over resources and personal growth and development. In practice with the proposed business here, job-enrichment could be taking from within each production unit. This might bring the following benefit:

1). Job-enrichment integrates job description in vertical direction, which shortens the top - bottom distance without changing whole structure design. It not only meets the need of hierarchy control but also match UAI indicator of French culture.

2). The original choice of SARL style is in order to remove unnecessary layer of the new small business, vertical combination of job could restrict the company at a necessary size, which could effectively reduce labor cost since higher wage is real factor harm the company's development in France.

In addition, a number of multinational IT companies like HP and XEROX located their European head-office or $\mathrm{R} \& \mathrm{D}$ department in Grenoble. This provides very strong IT service platform those businesses around this area. Thus, well - utilizing available IT platform to exercise business is another way to reduce cost. For instance, through own company web-page or e-business, it could deliver ski resorts service to every corner of the world without large human resource input.

\section{Conclusion}

The discussion is round political, environmental and economic factors. Through this investigation, it is clear that French taxation system is real element harmful for the development of new business, and it is the main reason cause high level unemployment as well as strong Euro negatively affect the market in some degree, however, high unemployment level in turn create the opportunity to purchase relative cheap labor. At the same, using different benchmark measure the impact of Euro, ski resort service business might face a large market with high profit and less competition. Indeed, once comprehensively and deeply analysis the economic situation, it is not impossible to find some new profit area, even in a relative weak economy circumstance.

This report highlight how to organize a new company within a particular legal and culture background, using the combination of accounting and organizational behavior knowledge is in order to design amore efficient and cost less organization. In addition, appropriately arrange a firm could largely, at least partially offset some inevitable disadvantage create by the whole business environment. As Lynch motioned that one purpose the environment analysis is to discover reactive outcome. 
Thus, another gain from this research activity emphasize that integrating different discipline is a crucial way to achieve appropriate business decision. Consolidating broad perspectives is not only the effective method for decision making but also a re-question for improving management skill.

\section{References}

Sorensen-Bentham T. (2006). Strategy analysis tool. Brighton: Brighton Business School Press.

Gordon C. (1996). The business culture in France. Butterworth-Heinemann Press.

Begg D. (2005). Economics (8th ed). The McGraw Hill Companies, Inc..

Burns P \& Dewhurst J. (2004). Small business and entrepreneurship (2nd ed). MacMillan Business Press.

Gordon C. (1996). The business culture in France. Butterworth Heinemann Press.

Martin J. (2005). Organizational behavior and management (3rd ed).Thomson Press.

Mullins L J. (2005). Management and organizational behavior (7th ed). Prentice Hall Press.

Pendlebury M, Groves R. (2004). Company accounts (6th ed). Thomson Press.

Randlesome C W, et al. (1993). Business cultures in Europe (2nd ed). Butterworth Heinemann Press.

Samuelson P A \& Nordhaus W D. (2005). Economics (17th ed). The McGraw Hill Companies, Inc..

Table 1. Total tax burden in 2004 ( $\%$ of GDP)

\begin{tabular}{l|l|l}
\hline & fiscal & social \\
\hline France & 11.1 & 18.4 \\
\hline UK & 15.6 & 8.2 \\
\hline Sweden & 19.6 & 14.8 \\
\hline Latvia & 8.0 & 9.0 \\
\hline
\end{tabular}

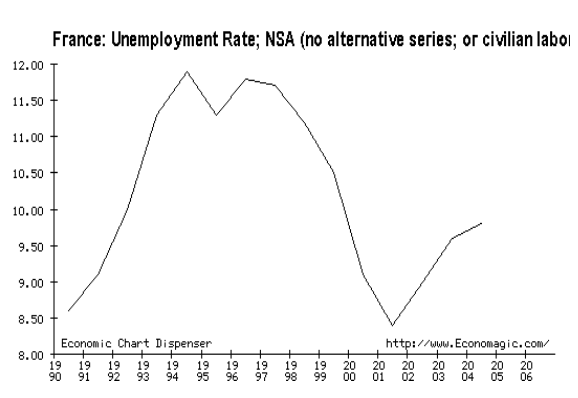

Figure 1

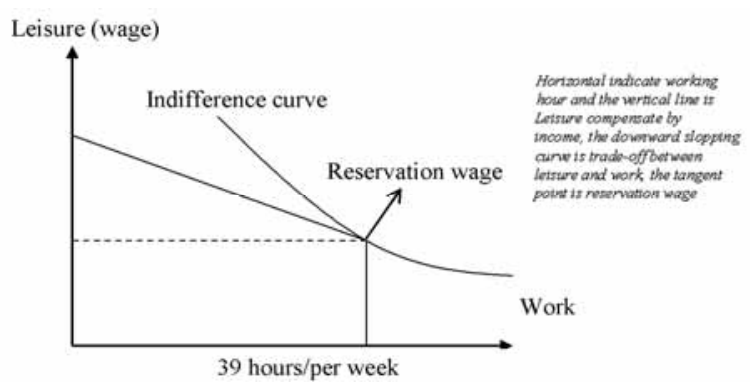

Figure 3
Table 2. Unit labour cost in 2004 in terms of Euro (€)

\begin{tabular}{l|l}
\hline Germany & 27.9 \\
\hline France & 27.7 \\
\hline UK & 23.6 \\
\hline US & 18.1 \\
\hline
\end{tabular}

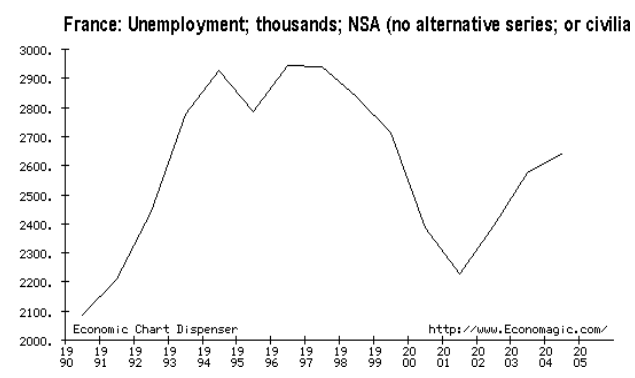

Figure 2

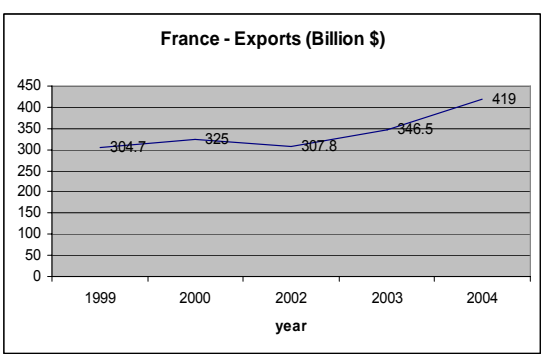

Figure 4 


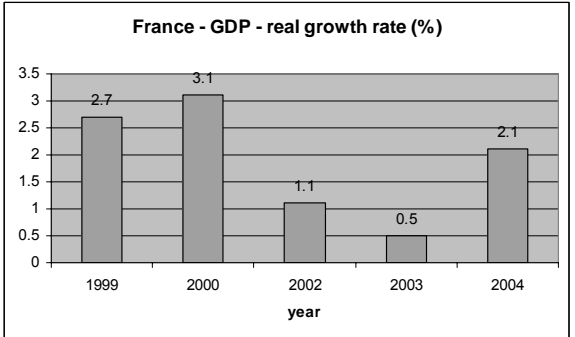

Figure 5

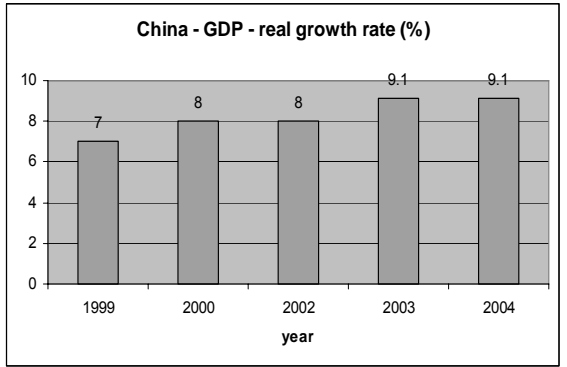

Figure 7

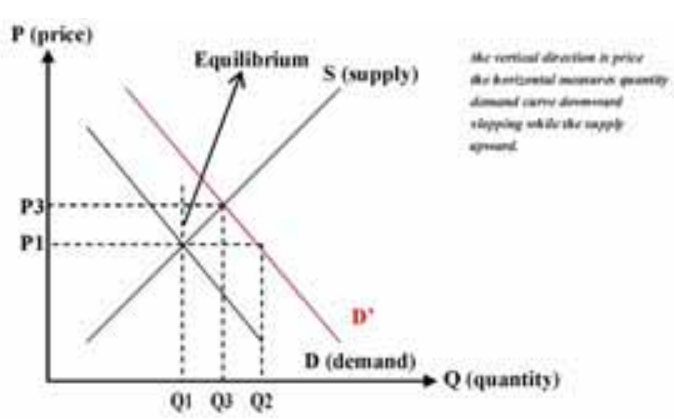

Figure 9

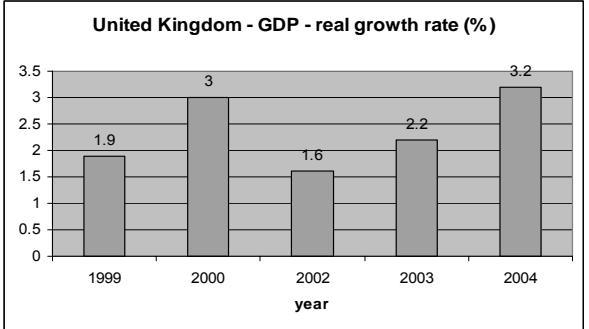

Figure 6

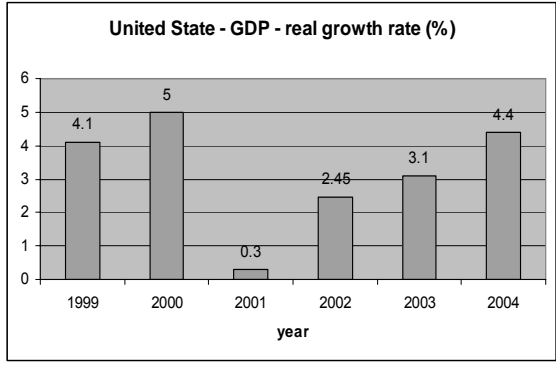

Figure 8

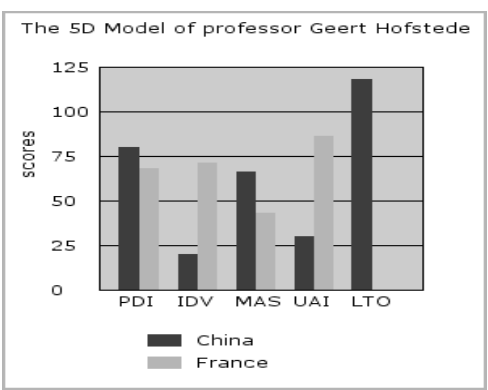

Figure 10

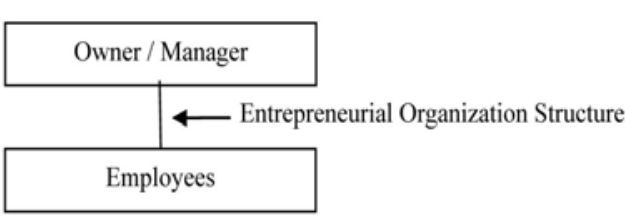

Figure 11

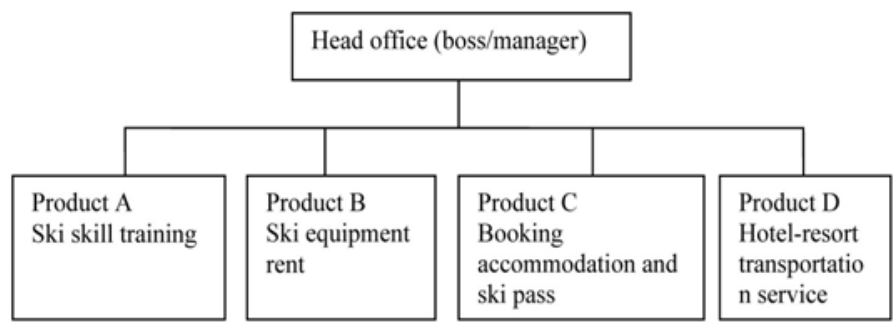

Figure 12

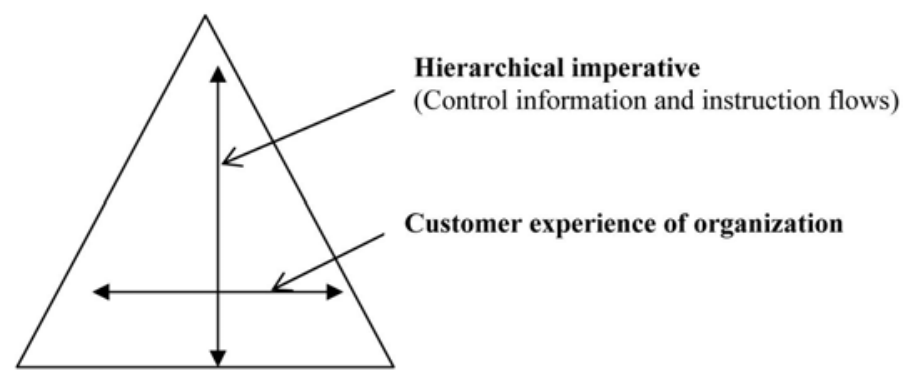

Figure 13 